\title{
Wall-to-Bed Heat Transfer at Minimum Gas-Solid Fluidization
}

\author{
Huili Zhang, ${ }^{1}$ Jan Degrève, ${ }^{1}$ Jan Baeyens, ${ }^{2}$ and Raf Dewil ${ }^{3}$ \\ ${ }^{1}$ Department of Chemical Engineering, KU Leuven, Chemical and Biochemical Process Technology and Control Section, \\ de Croylaan 46, 3001 Heverlee, Belgium \\ ${ }^{2}$ School of Engineering, University of Warwick, Coventry, UK \\ ${ }^{3}$ Department of Chemical Engineering, KU Leuven, Process and Environmental Technology Lab, J.P. De Nayerlaan 5, \\ 2860 Sint-Katelijne-Waver, Belgium
}

Correspondence should be addressed to Jan Baeyens; baeyens.j@gmail.com

Received 7 May 2014; Accepted 3 September 2014; Published 17 September 2014

Academic Editor: Clive E. Davies

Copyright (c) 2014 Huili Zhang et al. This is an open access article distributed under the Creative Commons Attribution License, which permits unrestricted use, distribution, and reproduction in any medium, provided the original work is properly cited.

The heat transfer from a fluidized bed to the cooling jacket of the vessel has been studied for various powders at minimum fluidization conditions, by both convection and conduction approaches. These heat transfer characteristics are important as the point of transition between packed and fluidized bed operations and are needed in designing heat transfer operations where bubbleflow is not permitted. The effective thermal conductivity of the emulsion moreover determines the contact resistance at the heating or cooling surface, as used in packet renewal models to predict the wall-to-bed heat transfer. In expressing the overall heat transfer phenomenon as a convective heat transfer coefficient, it was found that the results could be fitted by $\mathrm{Nu}_{\mathrm{mf}, j}=0.01 \mathrm{Ar}^{0.42}$.

\section{Introduction}

A powder is a heterogeneous system in which solid particles are surrounded by gas. There are an unlimited number of solid-gas systems possible ranging from the single solid in single gas system to the more complex fluidized bed.

The specific reasons for investigating the heat transfer at minimum fluidization are fourfold: (i) it is an important design value for operations where bubble-flow is not permitted, for example, cooling of safety glass or slow and controlled cooling/hardening of metal-alloy wire; (ii) it is the point of transition between packed and fluidized bed operations; (iii) it defines the extent of the thermal gradient within the bed close to the heat exchanging wall; and (iv) it provides data of the effective thermal conductivity of the bed at minimum fluidization: data on the effective thermal conductivity are essential to the estimation of the contact resistance at the heating or cooling surface, as used in packet renewal models to predict the wall-to-bed heat transfer and further discussed in Section 3.4.

Attempts to understand how heat is transferred through the system usually devolve into attempts to determine its "convective heat transfer coefficient," $h\left(\mathrm{~W} / \mathrm{m}^{2} \mathrm{~K}\right)$, as defined in the standard equation for heat transfer by convection:

$$
Q=h A_{\mathrm{ex}} \Delta T \text {. }
$$

Experiments allow the determination of the temperature difference $(\Delta T$, in $K)$ for a known heat flow rate, $Q,(W)$ and a known surface area of the heat exchanger $A_{\text {ex }}\left(\mathrm{m}^{2}\right)$. The heat exchange surfaces are either an "outside-wall," that is, a heat transfer jacket, or an "internal" surface with an immersed tubular heat exchanger. Both experimental and industrial equipment commonly use cylindrical configurations to contain the bed, often with immersed tubular heat exchanger and/or heat transfer jacket.

The heat transfer coefficient in bubbling fluidized beds has been extensively investigated (e.g., [1-4]): the wall-tobed heat transfer rate increases with increasing gas flow rate because of the more vigorous bubble-induced particle mixing and hence a faster renewal of the emulsion phase in contact with the heat exchange surface (Figure 1). The increase is however limited, since higher gas flow rates cause a longer time fraction of contact between the gas bubbles and the surface. This phenomenon will even dominate at very 
high gas flow rates, where the heat transfer coefficient will gradually decrease $[5,6]$. In deep fluidized beds of smaller internal diameter, the freely bubbling mode can transform into slugging $[7,8]$, where again poorer mixing and long slug contact with the heat transfer surface will reduce the heat transfer coefficient [6].

This bubble-induced heat transfer mechanism is illustrated in Figure 1, where packets of particles are brought into contacting the transfer surface, absorbing heat during their contact by unsteady state conduction and dissipating the captured heat into the bulk of the bed by the bubble-induced mixing. This packet renewal mechanism will be discussed in Section 3.4 of the paper.

A different approach to describing the heat transfer by convection considers conduction through the emulsion phase in contact with the heat transfer surface. This approach results in the determination of the thermal conductivity, $k(\mathrm{~W} / \mathrm{mK})$. This property of the system determines the temperature gradient under a fixed heat flow. The definition of $k$ is obtained from Fourier's law

$$
Q=-k A_{\mathrm{ex}} \frac{\Delta T}{\Delta x},
$$

where the heat flow rate, $Q,(\mathrm{~W})$ and the temperature gradient, $\Delta T / \Delta x,(\mathrm{~K} / \mathrm{m})$ are perpendicular to the exchange area, $A_{\text {ex }}\left(\mathrm{m}^{2}\right)$.

Integration of (2) for a cylindrical space with height $L(\mathrm{~m})$ and for radii $r_{1}$ and $r_{2}(\mathrm{~m})$ leads to expressions for the radial thermal conductivity as illustrated in Figure 2.

The radial thermal conductivity, $k_{r}(\mathrm{~W} / \mathrm{mK})$, is determined by the geometry, the radial heat flow, $Q_{r},(\mathrm{~W})$, and the temperature difference $\Delta T(\mathrm{~K})$, according to

$$
k_{r}=\frac{Q_{r}}{2 \pi L \Delta T} \ln \left(\frac{r_{2}}{r_{1}}\right) .
$$

Thermal conductivities may be measured by either static or dynamic methods. The former involves temperature measurements under steady state operation whereas in the latter case the temperature change with time is measured at one or more positions. Since confidence in unsteady state methods is usually based on agreement with steady state methods, the use of the former seems desirable until a fairly comprehensive collection of reliable data has been acquired. The specific study of thermal conductivities in fluidized bed is uncommon since it is often impossible to measure a thermal gradient in the bulk of the bed, due to the high thermal conductivity, due to the relatively small heat fluxes used in the experiments, and due to the temperature fluctuations in the bed [6]. It is also known from experiments that the axial conductivity is about 10 times greater than in the radial direction, due to the better axial mixing in the wake of a bubble, as mentioned by Rowe et al. [9].

The experimental heat transfer surface could be a plane slab, a hollow sphere, or a cylinder but since the construction of uniform hollow spheres or slabs is very difficult, cylindrical arrangements are very common and have been used in most of the previous experiments, as reviewed by Grace and Baeyens [10].

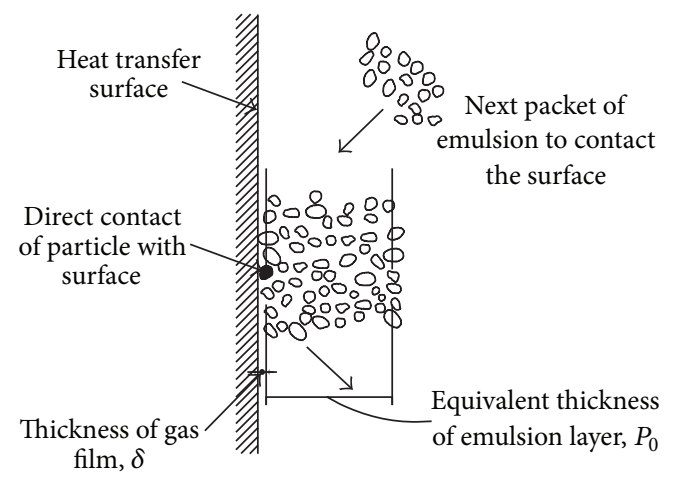

FIGURE 1: General mechanism of bed-to-wall heat transfer.

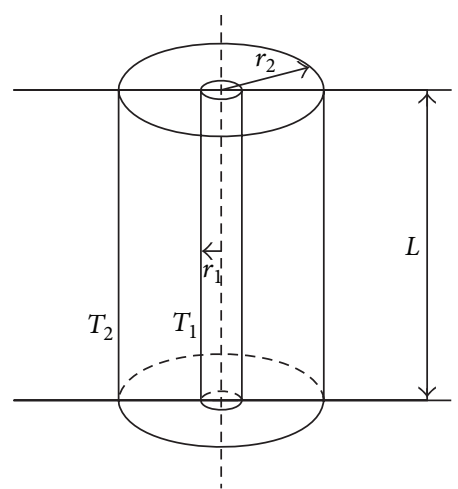

FIGURE 2: Geometry for the radial heat flow in a cylindrical unit.

Ideally, only a heat flow perpendicular to the surface should occur. For the study of radial heat transfer, the flat end surfaces of the cylinder ought to be covered with a nonconductor of heat. As there is no such perfect insulator, two techniques are frequently used: heat guards are used in order to keep the temperature constant over the whole length of the test section, or results are only taken in the centre section of a test specimen which is long in comparison to its diameter and where the isothermal surfaces are essentially cylindrical over the centre section. In the present study the guard-heater approach will be used, as described further in the text.

\section{Experimental Layout and Procedure}

The experiments involved the use of a mild steel fluidization column of $21.6 \mathrm{~cm}$ I.D., whereby the fluidized bed was heated with an immersed electrical heater and cooled by water circulating in the jacket of the column. The equipment is schematically represented in Figure 3.

The water jacket is the annular space between the $21.6 \mathrm{~cm}$ bed and the outer $25 \mathrm{~cm}$ I.D. pipe. Cold water from the service pipe $\left(T \approx 20^{\circ} \mathrm{C}\right)$ was fed to a constant head tank, and a needle valve in the underflow controlled the flow rate. The water flow meter was calibrated by measuring the volume of water collected over a measured time. The central heater consisted 


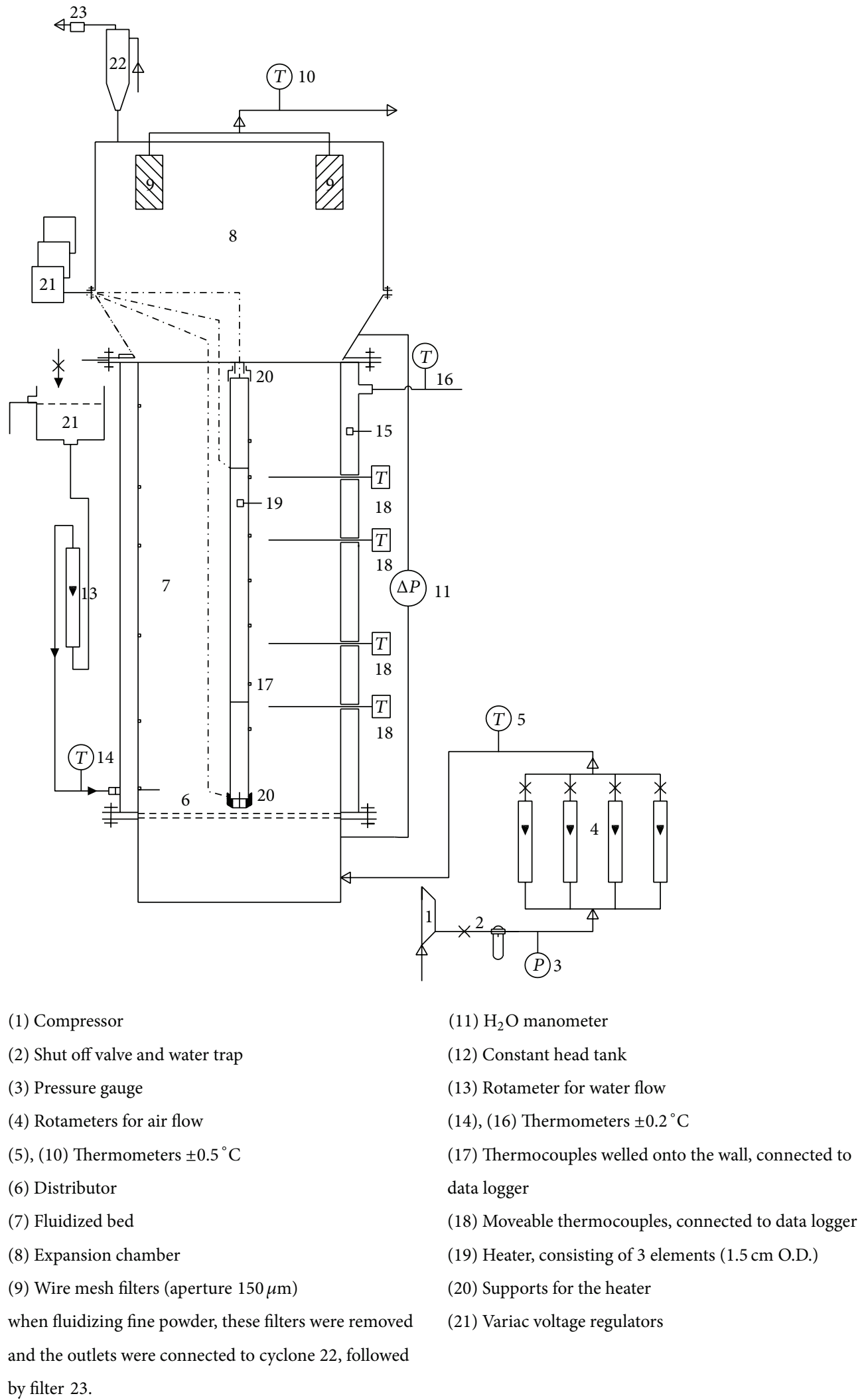

FIGURE 3: Layout of the experimental rig. 
of three heater elements, manufactured by Masser [11]: the middle heater was $300 \mathrm{~mm}$ long and the guard heaters were each $100 \mathrm{~mm}$. These elements were incorporated in a copper tube $(\approx 10 \mathrm{~mm}$ I.D. $-15 \mathrm{~mm}$ O.D. $)$ and the complete heater was positioned centrally in the column by means of a brass tube fixed onto the distributor at the bottom of the heater and by means of 2 radial rods supporting a central brass tube fixed to the top of the heater. By using the guard heaters a nearly constant temperature along the full length of the middle heating element was obtained.

Thermocouples were imbedded in the heater wall and brazed into position. The bed temperature was measured with moveable sheathed thermocouples at different radial positions and four different heights. These thermocouples with stainless steel sheaths were fixed with Araldite into a $2 \mathrm{~mm}$ O.D. copper tube to prevent them bending at the tip. The thermocouples protruded $10 \mathrm{~mm}$ beyond the supporting tubes. The thermocouples were moved in steps of $\sim 1 \mathrm{~mm}$ in the vicinity of the heater and $5 \mathrm{~mm}$ in the bulk of the bed. The position of the thermocouples was defined with an accuracy of $0.5 \mathrm{~mm}$ by means of a mark on the copper sheath.

The thermocouple outputs, with $0.5^{\circ} \mathrm{C}$ accuracy, were connected to a data logger. The experimental work involved the use of 21 powders and the static bed height was about $50 \mathrm{~cm}$ for all powders tested. The minimum fluidization velocity was determined from the commonly used measurement of the pressure drop across the bed, $\Delta P(\mathrm{~Pa})$, at increasing superficial gas velocity, $U(\mathrm{~m} / \mathrm{s})$ [12]. The air flow rate was adjusted to the superficial gas velocity at minimum fluidization, $U_{\mathrm{mf}}(\mathrm{m} / \mathrm{s})$, where the first small bubbles occurred at the bed surface. Almost all of the powders tested are of the Geldart B-type [12], where the onset of bubbling and the condition of minimum fluidization coincide. The onset of bubbling occurs at a higher gas velocity than $U_{\mathrm{mf}}$ only for A-type powders. The heater was switched on and the bed was allowed to reach steady state conditions, resulting in a constant temperature at the heater and in the bed. The temperatures were recorded over 30 minutes and the voltage across the heater was measured with an AVO-meter. The experimental results will be described hereafter.

The gas distributor was a sandwich of filter paper between two perforated metal plates, with $8 \mathrm{~mm}$ I.D. holes at a $25.4 \mathrm{~mm}$ pitch, as illustrated in Figure 4 .

Three Variac voltage regulators were used. While centrally heating and simultaneously cooling (wall), local temperatures in the bed and at the inner and outer walls were measured. The details of thermocouple locations on both surfaces and in the bed are given in Figure 3. The powder sphericity and solids' thermal conductivity, $k_{s}(\mathrm{~W} / \mathrm{mK})$, are given in Table 1.

\section{Experimental Results and Discussion}

3.1. Temperature Profiles and Heat Transfer Properties. From the experiments, graphs similar to Figure 5 were obtained whilst the use of guard heaters maintained the temperature at the heater wall to within $2^{\circ} \mathrm{C}$ over the entire height. The temperature of the jacket was also nearly independent

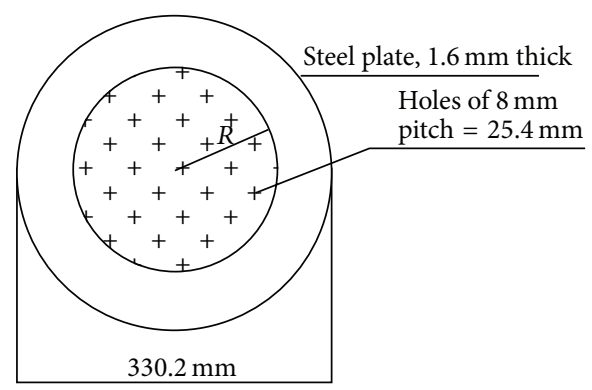

FIGURE 4: Perforated plate distributor used for testing.

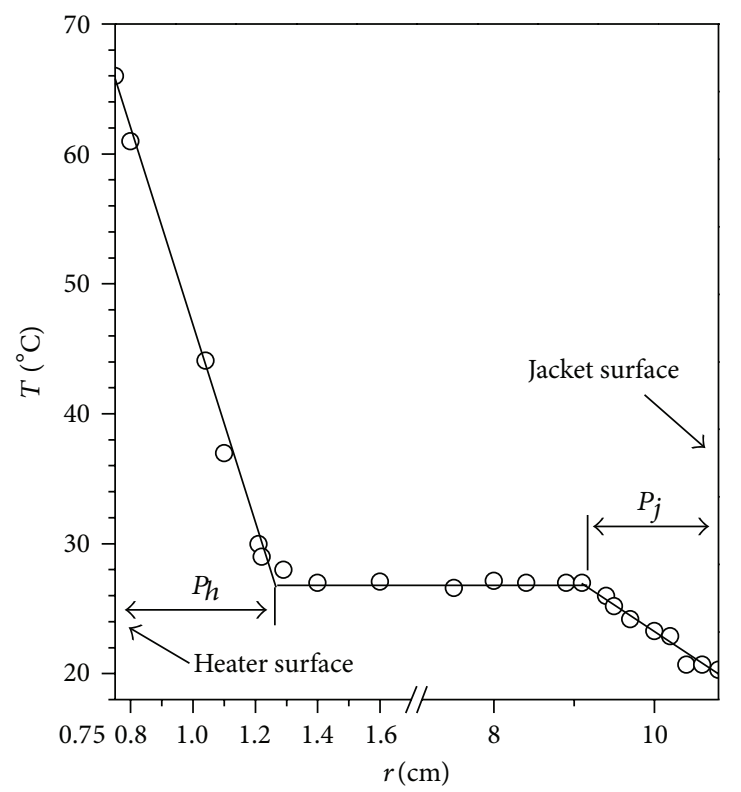

FIGURE 5: Semilogarithmic plot of the average temperature $T$ versus radial distance $r$.

TABle 1: Properties of the components of the powder gas system used in calculations.

\begin{tabular}{lcc}
\hline Powder & Sphericity, $\psi(-)$ & $k_{s}(\mathrm{~W} / \mathrm{mK})$ \\
\hline Silica sand & $0.85=$ rounded & 0.180 \\
Glass beads & $0.67=$ angular & 0.092 \\
Cracking catalyst & 1.0 & 0.138 \\
Diakon spheres & 0.60 & 0.243 \\
\hline
\end{tabular}

of height in the bed (within $1.5^{\circ} \mathrm{C}$ ). $\Delta T$ could be readily calculated from arithmetic means.

The heater output was typically $25.2-33.6 \mathrm{~W}$. The cooling output from the bed to the jacket was calculated from the known water flow rate and the measured temperature difference of the water between input and output to the jacket. The surface area of the jacket was calculated as $\pi * 21.6 *$ $H_{\mathrm{mf}} \mathrm{cm}^{2}$, where $H_{\mathrm{mf}}$ is the bed height at incipient fluidization (close to $50 \mathrm{~cm}$ in all runs). 
TABLE 2: Experimental results in the $21.6 \mathrm{~cm}$ I.D bed using a $1.0 \mathrm{~cm}$ O.D. heater.

\begin{tabular}{|c|c|c|c|c|c|c|c|}
\hline Powder & $\overline{d_{\mathrm{sv}}}(\mu \mathrm{m})$ & $\rho_{s}\left(\mathrm{~kg} / \mathrm{m}^{3}\right)$ & $U_{\mathrm{mf}}^{*}(\mathrm{~cm} / \mathrm{s})$ & $\varepsilon_{\mathrm{mf}}^{*}(-)$ & $h_{\mathrm{mf}, j}^{*}\left(\mathrm{~W} / \mathrm{m}^{2} \mathrm{~K}\right)$ & $P_{j}^{*}(\mathrm{~cm})$ & $\begin{array}{c}k_{\mathrm{mf}, j}=h_{\mathrm{mf}, j} \cdot P_{j} \\
(\mathrm{~W} / \mathrm{mK})\end{array}$ \\
\hline \multirow{5}{*}{ Glass beads } & 55 & 2800 & 0.32 & 0.466 & 16.6 & 3.5 & 0.58 \\
\hline & 96 & 2800 & 0.95 & 0.457 & 18.6 & 2.9 & 0.54 \\
\hline & 173 & 2800 & 3.6 & 0.442 & 20.2 & 2.5 & 0.51 \\
\hline & 208 & 2800 & 3.8 & 0.440 & 22.8 & 2.4 & 0.55 \\
\hline & 407 & 2800 & 8.2 & 0.425 & 21.3 & 1.9 & 0.40 \\
\hline \multirow{6}{*}{ Angular sand } & 90 & 2540 & 1.23 & 0.590 & 18.3 & 3.3 & 0.60 \\
\hline & 106 & 2540 & 1.37 & 0.563 & 19.0 & 3.2 & 0.61 \\
\hline & 252 & 2540 & 5.3 & 0.498 & 32.1 & 2.6 & 0.83 \\
\hline & 470 & 2540 & 19.1 & 0.429 & 29.9 & 2.2 & 0.66 \\
\hline & 550 & 2540 & 29.5 & 0.414 & 34.0 & 2.1 & 0.71 \\
\hline & 778 & 2540 & 50.1 & 0.405 & 38.3 & 2.0 & 0.77 \\
\hline \multirow{5}{*}{ Rounded sand } & 152 & 2650 & 1.8 & 0.487 & 23.2 & 2.6 & 0.60 \\
\hline & 195 & 2650 & 3.2 & 0.432 & 23.8 & 2.4 & 0.57 \\
\hline & 197 & 2650 & 3.1 & 0.469 & 23.0 & 2.4 & 0.55 \\
\hline & 252 & 2650 & 4.9 & 0.453 & 25.9 & 2.2 & 0.57 \\
\hline & 435 & 2650 & 16.8 & 0.416 & 25.3 & 1.8 & 0.46 \\
\hline Diakon spheres & 270 & 1180 & 3.3 & 0.426 & 23.3 & 2.2 & 0.51 \\
\hline \multirow{4}{*}{ Catalyst } & 38 & 1500 & 0.17 & 0.545 & 16.1 & 3.8 & 0.61 \\
\hline & 46 & 1500 & 0.23 & 0.543 & 12.5 & 3.7 & 0.46 \\
\hline & 58 & 1630 & 0.26 & 0.504 & 12.8 & 3.6 & 0.46 \\
\hline & 64 & 1630 & 0.28 & 0.502 & 14.5 & 3.6 & 0.52 \\
\hline
\end{tabular}

Note: properties marked $*$ were experimentally determined. Average particle sizes were measured by Malvern laser diffractometry. The absolute particle density was taken from suppliers' data.

Experiments were repeated 3 times for each powder, and the respective calculated heat transfer coefficients were all within $7 \%$ of the calculated (and further reported) average values. The experimental temperature profiles, as illustrated in Figure 5, demonstrate the existence of a distinct zone near the central heater or near the outside-wall where a major temperature gradient is observed. These thicknesses of these zones are given in Figure 5 as $P_{h}$ and $P_{j}$ for the heater and wall zones, respectively. The temperature gradients in these contact layers are significant. The temperature remains however nearly constant outside these layers, that is, in the central part of the bed. These zones correspond to the contact transfer layers in the mechanistic surface renewal models (e.g., [13-16]). This differs from a packed bed, where the thermal gradient extends from centre to wall [17]. The overall properties of such layers can be derived if their cylindrical symmetry is taken into account. This has been performed graphically on the semilogarithmic plots of the gradient thicknesses of the layer near the outer wall. With determined heat transfer coefficients and layer thicknesses, the effective thermal conductivity of the layers near the jacket can be calculated and values of the thermal conductivity at minimum fluidization near the jacket, $k_{\mathrm{mf}, j}(\mathrm{~W} / \mathrm{mK})$, are included in Table 2.
3.2. The Convective Bed-to-Wall Heat Transfer Coefficients at Minimum Fluidization. All wall-to-bed convection heat transfer coefficients at minimum fluidization, $h_{\mathrm{mf}, j}$, were transformed into their respective Nusselt-numbers $\left(h_{\mathrm{mf}, j} d_{\mathrm{sv}} / k_{g}\right)$, with $k_{g}$ as thermal conductivity of the fluidization gas $(\mathrm{W} / \mathrm{mK})$.

The particle size, $d_{\mathrm{sv}}(\mathrm{m})$, absolute particle density, $\rho_{p}$ $\left(\mathrm{kg} / \mathrm{m}^{3}\right)$, gas density, $\rho_{g}\left(\mathrm{~kg} / \mathrm{m}^{3}\right)$, gas viscosity, $\mu(\mathrm{kg} / \mathrm{ms})$, and the gravitational constant, $g\left(\mathrm{~m} / \mathrm{s}^{2}\right)$, were grouped into the Archimedes number, defined as

$$
\operatorname{Ar}=\frac{d_{\text {sv }}^{3}\left(\rho_{p}-\rho_{g}\right) \rho_{g} g}{\mu^{2}} .
$$

The increase of the minimum fluidization heat transfer coefficient with increasing $d_{\mathrm{sv}}$ is due both to a higher value of the gas flow, hence increasing the effect of forced convection, and to a decreased voidage. A log-log plot of Nusselt number versus Archimedes number for all powders tested yields a straight line, as illustrated in Figure 6, suggesting a correlation of the form $\mathrm{Nu}_{\mathrm{mf}, j}=K \mathrm{Ar}^{c}$, where $K$ and $c$ have values as given in (6), for $10 \leq \mathrm{Ar} \leq 2 * 10^{3}$ :

$$
\mathrm{Nu}_{\mathrm{mf}, j}=0.01 \mathrm{Ar}^{0.42} \text {. }
$$




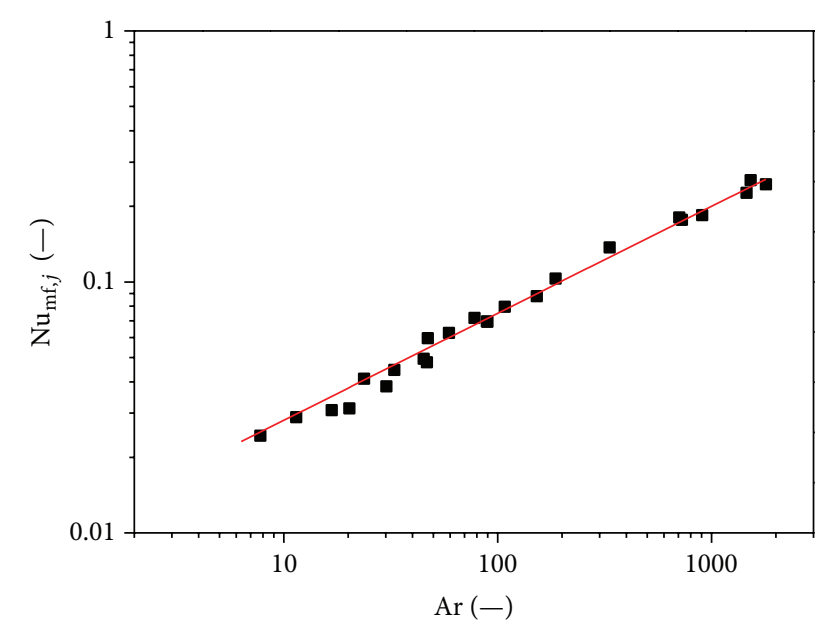

FIgURE 6: Nusselt number versus Archimedes numbers for all 21 powders tested.

A comparison of our results with former investigations is very difficult because these researchers either only represented their data graphically, or included no precise data in the vicinity of $U_{\mathrm{mf}}$.

3.3. The Effective Thermal Conductivity. As already mentioned, Figure 5 suggests that heat is being conducted away from the heater or jacket through a distance of $P_{0} \mathrm{~cm}$, characterizing the contact thermal layer, and thereafter nearisothermal conditions prevail in the bed. Values are presented in Figure 7.

It can be seen that the thickness $P_{0}$ has a higher value for fine particles than for coarser ones and the same trend exists for spherical/rounded materials versus angular powders. If the heat transfer were purely conductive, one would expect the opposite trend. It should be remembered however that the mechanism of heat transfer includes a transfer to the gas. Due to the deflection of the gas stream by the particles, a complex gas flow pattern (counter current, concurrent, and perpendicular to the heat flow) is responsible for the radial dispersion of the heat. Since the interstitial gas velocity in any direction increases as the bed voidage at minimum fluidization $\left(\varepsilon_{\mathrm{mf}}\right)$ decreases and the minimum fluidization velocity $\left(u_{\mathrm{mf}}, \mathrm{m} / \mathrm{s}\right)$ increases, it is clear that with increasing $d_{\mathrm{sv}}$ the convective radial heat interchange will increase and that the thermal gradient will be limited to a smaller zone near the wall only. The proposed thermal conductivity defines the radial temperature gradient and was introduced only because it was found impossible to describe the separate contribution of forced convection to the overall heat transfer.

Using the values of $k_{\mathrm{mf}, j}, h_{\mathrm{mf}, j}$ can be calculated for a particular solid-gas system from the use of the value of $P_{j}$ as given in Figure 7:

$$
h_{\mathrm{mf}, j}=\frac{k_{\mathrm{mf}, j}}{\left(R-P_{j}\right) \ln \left(R /\left(R-P_{j}\right)\right)},
$$

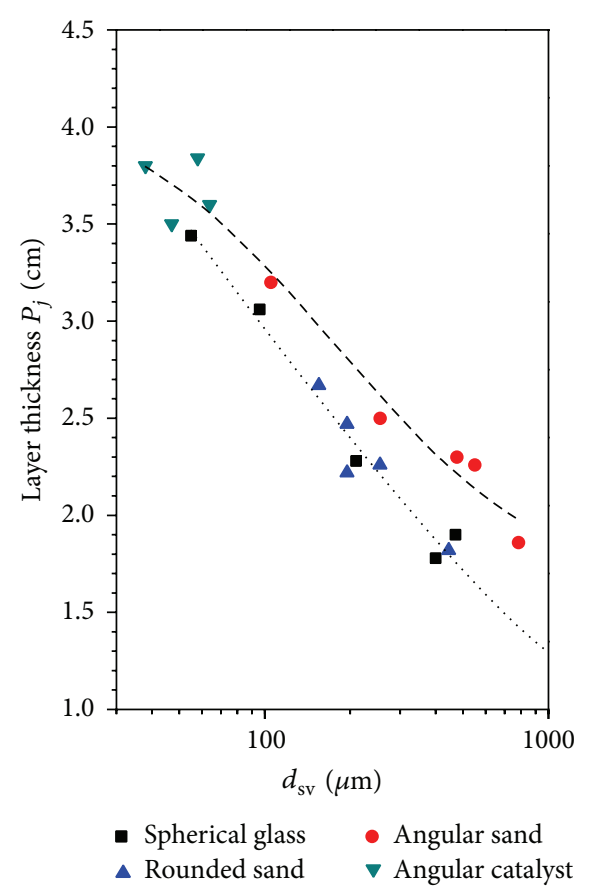

Figure 7: Average values of the layer thickness, $P_{j}$, versus particle size, $d_{\text {sv }}$.

where $R$ is the radius of the column. Smaller column diameters will hence see an increased value of the heat transfer coefficient.

3.4. The Contact Resistance in Heat Transfer Modelling. The heat transfer in gas-solid fluidized beds has been modelled by different approaches.

In single or multiple particle heat transfer models (e.g., [18-21]), the contact heat transfer is considered as a thin gas film adjacent to the heat transfer surface and of thickness $\delta$ $(\mathrm{m})$. The thermal conductivity of the gas, $k_{g}(\mathrm{~W} / \mathrm{mK})$, and the (unknown) thickness of the gas film (expressed as a fraction of the particle size, $d_{\text {sv }}$ ) define the contact resistance as

$$
h_{c}=\frac{k_{g}}{\delta},
$$

with $\delta$ equal to 0.1 to $0.2 d_{\mathrm{sv}}$.

In the packet renewal models (e.g., $[6,22,23]$ ), the thermal conductivity at minimum fluidization is recognized as basis of the heat transfer resistance.

Baeyens and Geldart [6] adapted the packet renewal model by adding a time-independent contact resistance, $h_{c}$ $\left(\mathrm{W} / \mathrm{m}^{2} \mathrm{~K}\right)$, between the packet and the surface, and determined this contact resistance as

$$
h_{c}=\frac{m \cdot k_{g}}{d_{\mathrm{sv}}} \sim \frac{k_{\mathrm{mf}}}{d_{\mathrm{sv}}} .
$$

Different values of $m$ have been given in literature, being 3.2 for nonmetallic powders [6], about 7.2 [24], to 8 [13], and 
even 10 [25]. The wide range of $m$-values cited in literature does not provide an unambiguous relationship between $k_{\mathrm{mf}}$ and $k_{g}$.

Having determined the thermal conductivity at minimum fluidization, $k_{\mathrm{mf}}$, the use of packet renewal models is however facilitated, since its value can be directly used in the expressions of the heat transfer coefficient, $h\left(\mathrm{~W} / \mathrm{m}^{2} \mathrm{~K}\right)$. This is illustrated for the expressions of two model approaches, as follows.

Mickley and Fairbanks [22]

$$
h=\sqrt{\frac{k_{\mathrm{mf}} \rho_{\mathrm{mf}} c_{p, \mathrm{mf}}}{\pi \theta}},
$$

Baeyens and Geldart [6]

$$
h=\frac{\pi h_{c}}{1+\left(6 h_{c} / \rho_{p} c_{p} d_{\mathrm{sv}}\right) \theta} \quad \text { with } h_{c} \sim \frac{k_{\mathrm{mf}}}{d_{\mathrm{sv}}} .
$$

The bubble-induced particle mixing determines the time of contact, $\theta(\mathrm{s})$, between the particles and the heat transfer surface [6]. Introducing the relevant particle properties and $k_{\mathrm{mf}}$ allows us to predict the heat transfer coefficient, $h$, at a given gas velocity and the packet contact time at the heat exchange surface, $\theta(\mathrm{s})$.

\section{Conclusions}

The heat transfer from a fluidized bed to the outside wall, at the onset of fluidization, has been studied for various powders.

In expressing the overall heat transfer phenomenon as a convective heat transfer coefficient, it was found that the results can be calculated from the equation $\mathrm{Nu}_{\mathrm{mf}}=$ $0.01 \mathrm{Ar}^{0.42}$.

Effective thermal conductivities were also predicted. A combination of the data of both the thicknesses of the thermal layer and the effective thermal conductivity allows prediction of the heat transfer coefficient for any geometry of the heat transfer surfaces, expressed by their respective radius, $R$. The measured thermal conductivity can moreover be applied in fluidized bed heat transfer modelling.

\section{Conflict of Interests}

The authors declare that there is no conflict of interests regarding the publication of this paper.

\section{Acknowledgment}

The authors acknowledge the European Commission for cofunding the "CSP2" Project-Concentrated Solar Power in Particles (FP7, Project no. 282 932).

\section{References}

[1] A. Stefanova, H. T. Bi, J. C. Lim, and J. R. Grace, "Local hydrodynamics and heat transfer in fluidized beds of different diameter," Powder Technology, vol. 212, no. 1, pp. 57-63, 2011.
[2] S. Sae-Heng, T. Swasdisevi, and M. Amornkitbamrung, "Investigation of temperature distribution and heat transfer in fluidized bed using a combined CFD-DEM model," Drying Technology, vol. 29, no. 6, pp. 697-708, 2011.

[3] Q. F. Hou, Z. Y. Zhou, and A. B. Yu, "Investigation of heat transfer in bubbling fluidization with an immersed tube," AIP Conference Proceedings, vol. 1207, pp. 355-360, 2010.

[4] V. A. Borodulya, V. L. Ganzha, Y. S. Teplitskii, and Y. G. Epanov, "Heat transfer in fluidized beds," Journal of Engineering Physics, vol. 49, no. 4, pp. 1197-1202, 1985.

[5] H. J. Bock and O. Molerus, "Influence of hydrodynamics on heat transfer in fluidized beds," Journal of Technical Writing and Communication, pp. 217-224, 1980.

[6] J. Baeyens and D. Geldart, "Modelling approach to the effect of equipment scale on fluidised bed heat transfer data," Journal of Powder \& Bulk Solids Technology, vol. 4, no. 4, p. 1, 1980.

[7] J. Baeyens and D. Geldart, "An investigation into slugging fluidized beds," Chemical Engineering Science, vol. 29, no. 1, pp. 255-265, 1974.

[8] R. K. Singh and G. K. Roy, "Prediction of minimum slugging velocity, bubbling bed index and range of bubbling fluidization in cylindrical and non-cylindrical gas-solid fluidized beds," Indian Journal of Chemical Technology, vol. 15, no. 1, pp. 85-89, 2008.

[9] P. N. Rowe, B. A. Partridge, and E. Lyall, "Cloud formation around bubbles in gas fluidized beds," Chemical Engineering Science, vol. 19, no. 12, pp. 973-985, 1964.

[10] J. R. Grace and J. Baeyens, "Instrumentation and experimental techniques," in Gas Fluidization Technology, D. Geldart, Ed., chapter 13, John Wiley \& Sons, Chichester, UK, 1986.

[11] Masser, http://www.masser.be/.

[12] D. Geldart, "Characterisation of fluidized powders," in Gas Fluidization Technology, D. Geldart, Ed., chapter 3, John Wiley \& Sons, Chichester, UK, 1986.

[13] A. P. Baskakov and O. K. Vitt, "Pulsations in coefficient of heat transfer from a surface submerged in a fluidized bed," Theoretical Foundations of Chemical Engineering, vol. 7, p. 812, 1973.

[14] X. S. Wang and M. J. Rhodes, "Determination of particle residence time at the walls of gas fluidized beds by discrete element method simulation," Chemical Engineering Science, vol. 58, no. 2, pp. 387-395, 2003.

[15] X. S. Wang and M. J. Rhodes, "A DEM study of particle motion near the walls of gas fluidized beds," Powder Technology, vol. 160, no. 1, pp. 15-19, 2005.

[16] M. M. Stojiljkovic, B. V. Stojanovic, J. N. Janevski, and G. S. Ilić, "Mathematical model of unsteady gas to solid particles heat transfer in Fluidized bed," Thermal Science, vol. 13, no. 1, pp. 5568, 2009.

[17] Z. Y. Zhou, A. B. Yu, and P. Zulli, "Particle scale study of heat transfer in packed and bubbling fluidized beds," AIChE Journal, vol. 55, no. 4, pp. 868-884, 2009.

[18] J. D. Gabor, "Wall-to-bed heat transfer in fluidized and packed beds," Chemical Engineering Progress Symposium Series, vol. 66, no. 105, pp. 76-86, 1970.

[19] J. D. Gabor, "Heat transfer to particle beds with gas flows less than or equal to that required for incipient fluidization," Chemical Engineering Science, vol. 25, no. 6, pp. 979-984, 1970.

[20] J. S. M. Botterill and J. R. Williams, "The mechanism of heat transfer to gas-fluidized beds," Transactions of the Institution of Chemical Engineers, vol. 41, no. 5, pp. 217-230, 1963. 
[21] F. Di Natale, A. Lancia, and R. Nigro, "A single particle model for surface-to-bed heat transfer in fluidized beds," Powder Technology, vol. 187, no. 1, pp. 68-78, 2008.

[22] H. S. Mickley and D. F. Fairbanks, "Mechanism of heat transfer to fluidized beds," AIChE Journal, vol. 1, no. 3, pp. 374-384, 1955.

[23] R. C. Brown and S. P. Overmann, "The influence of particle thermal time constants on convection coefficients in bubbling fluidized beds," Powder Technology, vol. 98, no. 1, pp. 13-20, 1998.

[24] S. S. Zabrodsky, Y. G. Epanov, D. M. Galershtein, S. C. Saxena, and A. K. Kolar, "Heat transfer in a large-particle fluidized bed with immersed in-line and staggered bundles of horizontal smooth tubes," International Journal of Heat and Mass Transfer, vol. 24, no. 4, pp. 571-579, 1981.

[25] J. S. M. Botterill, H. M. Butt, G. L. Cain, K. A. Redish, and K. A. Redish, "The effect of gas and solids thermal properties on the rate of heat transfer to gas-fluidised beds," in Proceedings of the International symposium on Fluidization, A. A. H. Drinkenburg, Ed., Netherlands University Press, Amsterdam, The Netherlands, 1967. 

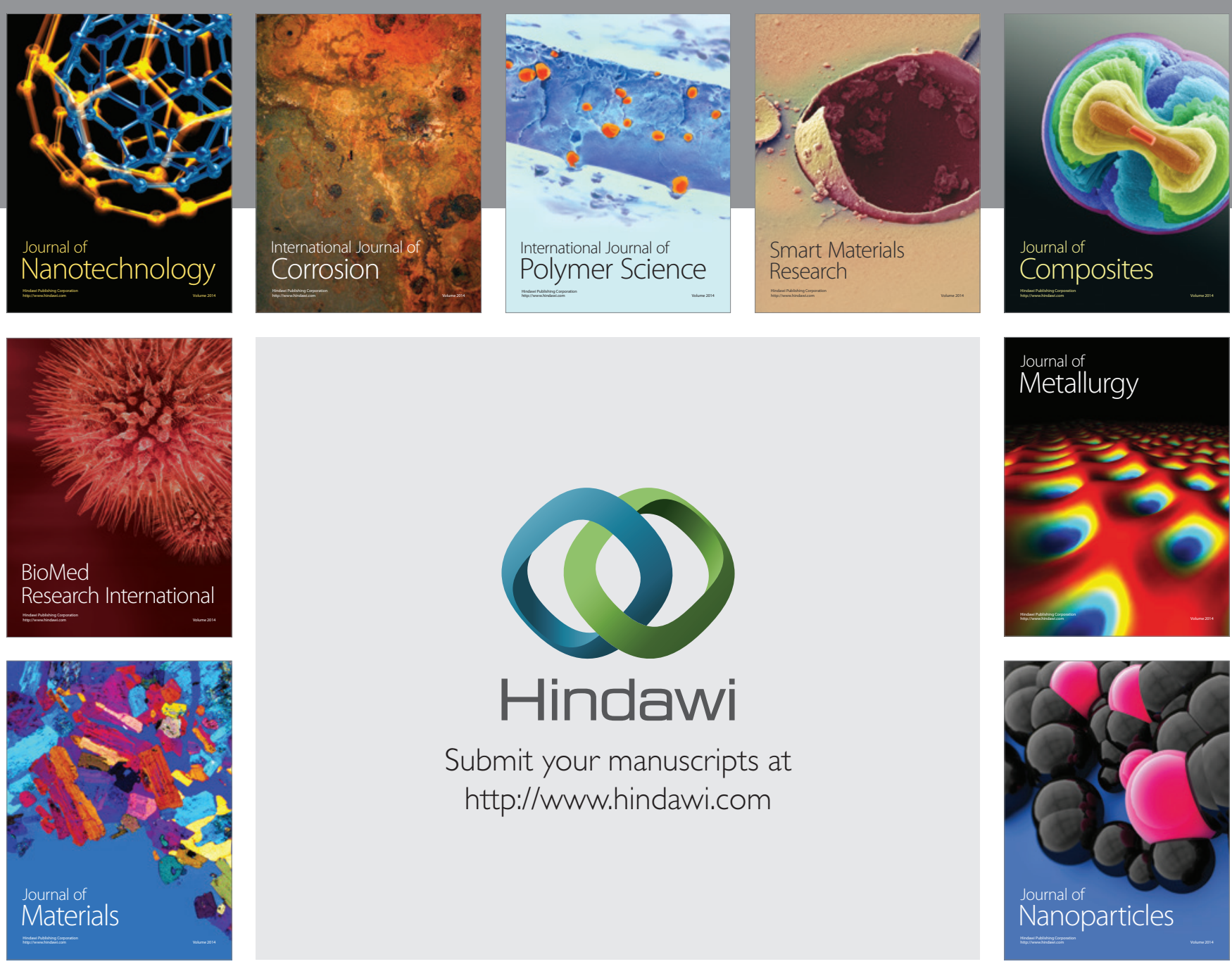

Submit your manuscripts at http://www.hindawi.com
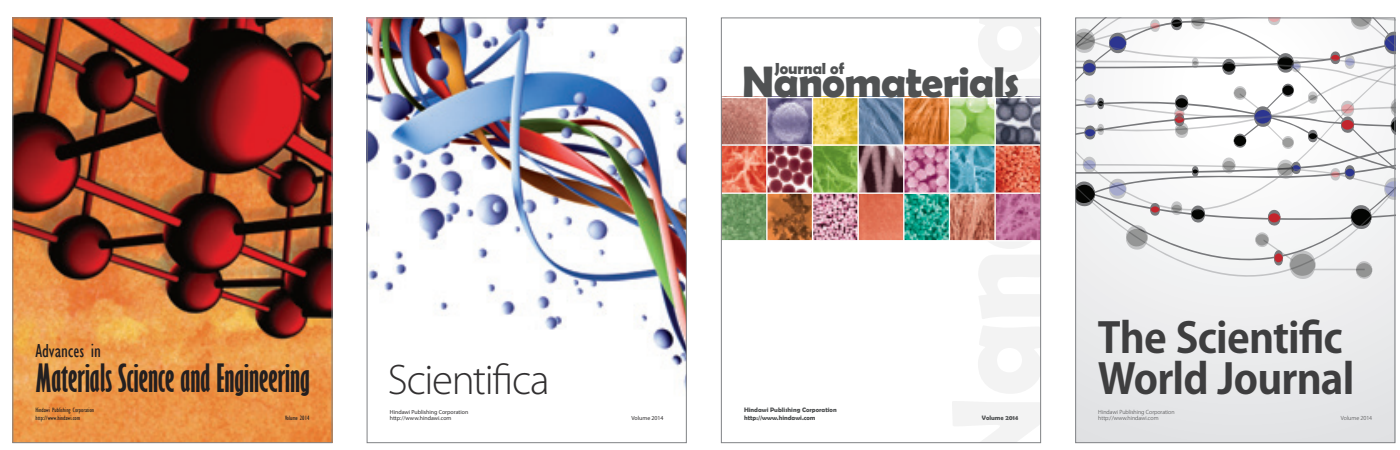

\section{The Scientific World Journal}
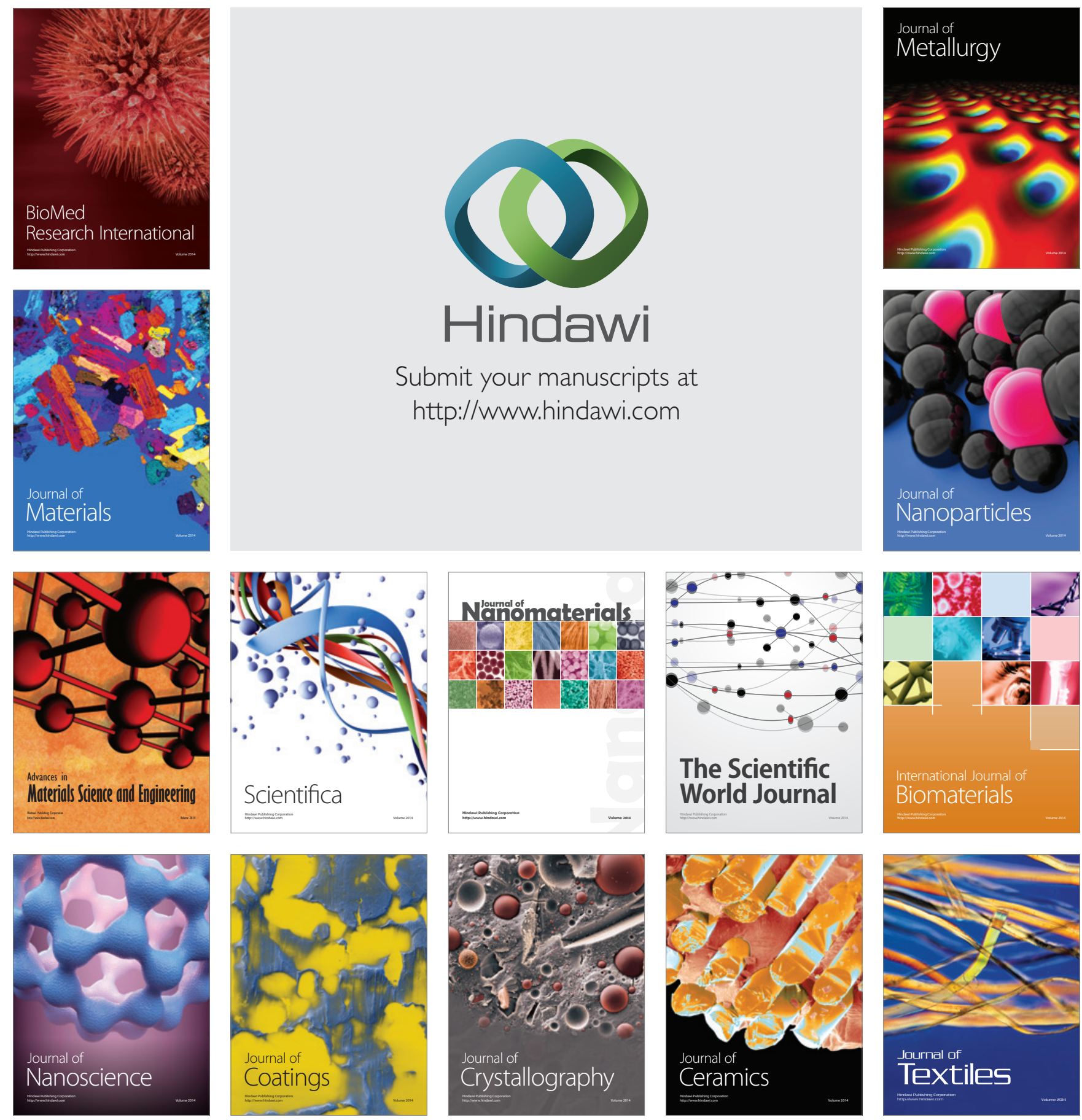